\title{
Pain, Stress and Anxiety of Chronic Pain Patients Prior to, During and After Political Turmoil in Thailand
}

\author{
Sasikaan Nimmaanrat, M.D., MMed', Tippawan Liabsuetrakul, M.D., Ph.D. ${ }^{2}$
}

${ }^{1}$ Department of Anesthesiology, ${ }^{2}$ Epidemiology Unit, Faculty of Medicine, Prince of Songkla University, Hat Yai, Songkhla 90110, Thailand.

Received 25 June 2018 • Revised 30 August 2018 • Accepted 6 September 2018 • Published online 17 October 2018

\section{Abstract:}

Objective: Thailand was plagued with serious political turmoil for many years. We would like to know whether this turmoil has had an impact on our chronic pain patients in terms of intensity of pain, stress and anxiety, as well as daily living and sleep.

Material and Methods: Patients with at least 3 months of pain prior to 31 October 2013 (the date that the demonstrations started) were enrolled in this study. The data were collected from the patients who attended our pain clinic from December 2014 to May 2015. The patients were asked to complete a questionnaire on their severity of pain, stress and anxiety for the 3 different stages: prior to the demonstrations (period 1), during the demonstrations (period 2) and under military dictatorship or after the demonstrations (period 3).

Results: There were 120 patients, 49 males (40.8\%) and 71 females (59.2\%). The mean age was $56.3 \pm 15.8$ years old (range 18-88). The majority were Buddhist (108 patients, 90.0\%) while 11 patients (9.2\%) were Muslim and 1 patient (0.8\%) was Christian. The mean duration of pain prior to the beginning of the demonstrations was 62.8 months (range 3-324 months). Regarding the pain score, the mean maximum pain score was significantly different between periods 1 (8), 2 (7.7) and 3 (6.8) (p-value<0.001). Regarding the anxiety score, the mean maximum anxiety score was significantly different between periods 1 (3.8), 2 (4.8) and 3 (2.9) ( $p$-value=0.03). Regarding the stress score, the mean maximum stress score was significantly different between periods 1 (3.8), 2 (4.4) and 3 (2.8) (p-value=0.02). Using multiple logistic regression analysis, no factors (gender, age, religious, duration of pain and levels of anxiety and stress) were found to have contributed to the reduction of pain intensity.

Conclusion: The demonstrations during the political turmoil did not increase the severity of pain but led to higher levels of stress and anxiety. On the other hand, under the military dictatorship, lower pain scores as well as stress and anxiety levels in chronic pain patients attending our pain clinic have been found.

Keywords: anxiety, military dictatorship, pain, politics, political crisis, political turmoil, stress

Contact: Sasikaan Nimmaanrat, M.D., MMed

Department of Anesthesiology, Faculty of Medicine, Prince of Songkla

University, Hat Yai, Songkhla 90110, Thailand.

Email: snimmaanrat@yahoo.com.au
J Health Sci Med Res 2018;36(4):291-298 DOI: http://dx.doi.org/10.31584/jhsmr.201827 www.jhsmr.org 


\section{Introduction}

Thailand had political turmoil for many years and its people have been affected by this long-term, seriously stressful political instability. The political crisis started roughly in 2005 and continued until the military took steps to terminate it in May 2014.

Thailand was divided into 2 main opposing sides in terms of political party preference. When one of the parties became the government there were anti-government protests from the other side and vice-versa, thus perpetrating a seemingly never ending cycle of unrest. The latest demonstrations took place on 31 October 2013 and were organized by the People's Democratic Reform Committee (PDRC). These demonstrations were initially activated by the proposed amnesty bill which was intended to pardon wrongdoing on all sides since 2004 and the proposed amendment to the 2007 constitution. Removal of the government (at that stage) from power and the establishment of an unelected People's Council to oversee political reforms were the demonstrations' goals.

On 20 May 2014, the Royal Thai Army intervened in the political crisis and martial law was imposed in Thailand. The army claimed that the action was not a coup d'état and a caretaker government remained in office. However, on 22 May 2014, the army formally staged a coup against the caretaker government and formed a junta, named the National Peace and Order Maintaining Council, to rule Thailand. On 21 August 2014, the army chief became the prime minister.

During the 7 months and 22 days of the demonstrations, the Thai People were psychologically influenced by the political turmoil to various degrees. We would like to know how these serious political situations affected our chronic pain patients in terms of level of pain, stress, and anxiety, as well as their consequences on daily living and sleep.

\section{Material and Methods}

This retrospective descriptive study was performed at our pain clinic from December 2014 until May 2015. This study has been approved by the institution's Ethics Committee. All the patients gave their written informed consent before participating in this study. The patients with persistent pain of at least 3 months prior to 31 October 2013 were enrolled in this study by completing a questionnaire. The questionnaire consisted of demographic data (gender, age, religion and duration of pain prior to the beginning of the PDRC demonstrations), pain intensity on a scale of 0-10 with $0=$ no pain and $10=$ the worst pain imaginable, stress intensity on a scale of $0-10$ with $0=$ no stress and $10=$ the worst stress imaginable, and anxiety intensity on a scale of $0-10$ with $0=$ no anxiety and $10=$ the worst anxiety imaginable. The patients were asked to retrospectively rate their minimum, average, and maximum pain score, stress score, and anxiety score, during the 3 different periods: prior to the demonstrations, during the demonstrations, and under the military dictatorship (after the demonstrations).

The questionnaire also considered the impact of the political crisis on chronic pain patients and included the direct question "Do you think that the political turmoil affected your level of pain?”. The responses were classified as no effect, alleviated pain, and aggravated pain. Moreover, the effects of the political turmoil on the patients' daily activities and sleep were evaluated and categorized as none, slight, moderate, and marked.

Data were recorded in Epidata 3.0 and analyzed using R version 3.3.1 (2016 The R Foundation for Statistical Computing, Austria). Continuous data were presented as mean \pm standard deviation (S.D.) or median with interquartile range as appropriate. Categorical data are presented as a percentage. The levels of pain, anxiety, and stress scores as main outcome measures over time were analyzed by variance and linear mixed-effects model fit 
by maximum likelihood. Multiple logistics regression was used to explore the association between demographic characteristics, duration of pain, anxiety, stress, and the change in pain scores from prior to and after the demonstrations. A p-value $<0.05$ is regarded as statistically significant.

\section{Results}

The demographic data, including gender, age, religion and duration of pain prior to the initiation of the PDRC demonstrations, are shown in Table 1. The majority of the patients were female $(59.2 \%)$ and the mean age was $56.3 \pm 15.8$ years old. Ninety percent were Buddhist and the duration of pain prior to the demonstrations varied from 3-324 months with a mean duration of 62.8 months.

Figure 1 presents the mean and 95.0\% confidence interval of minimum, average, and maximum pain scores by time. All pain scores at each stage showed significantly different levels of pain: after the demonstrations pain scores were significantly lower than prior to and during the demonstrations.

Table 1 Demographic characteristics of the patients

\begin{tabular}{ll}
\hline Characteristics & Number (\%) \\
\hline Gender & \\
Male & $49(40.8)$ \\
$\quad$ Female & $71(59.2)$ \\
$\quad$ Age (years) [mean \pm S.D.] & $56.3(15.8)$ \\
Religion & \\
Buddhist & $108(90.0)$ \\
Muslim & $11(9.2)$ \\
Christian & $1(0.8)$ \\
Duration of pain (months) & \\
Mean, min-max & $62.8(3-324)$ \\
$3-12$ & $29(24.8)$ \\
$12-84$ & $60(51.3)$ \\
$>84$ & $28(23.9)$ \\
\hline
\end{tabular}

S.D.=standard deviation
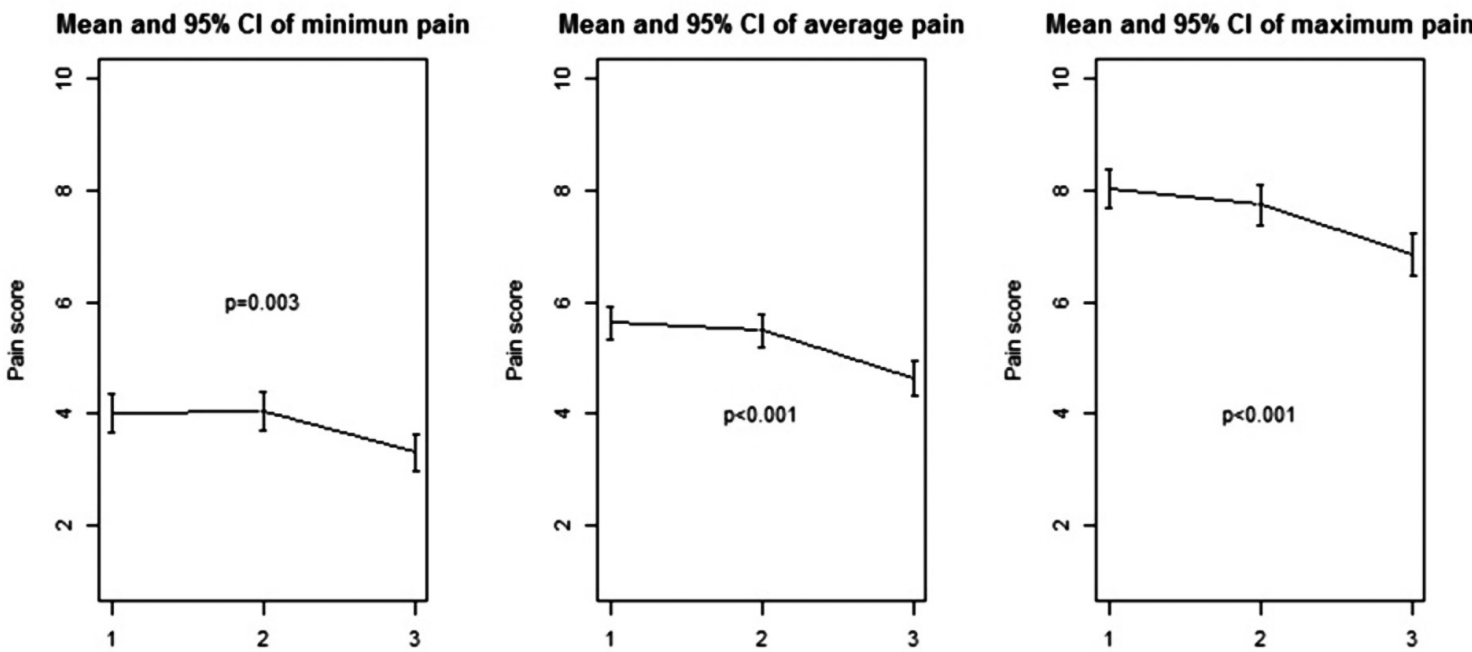

$1=$ prior to the demonstrations, $2=$ during the demonstrations, $3=$ under the military junta

$\mathrm{Cl}=$ confidence interval

Figure 1 The mean minimum, average, and maximum pain scores of the patients' prior to and during the demonstrations, as well as under the military junta 
The mean minimum pain scores \pm S.D. prior to the demonstrations, during the demonstrations, and under the military junta were 4 (1.9), 4 (1.9) and $3.3(1.8)$, respectively with a $p$-value of 0.003 . The mean average pain scores for the 3 periods were 5.6 (1.6), 5.5 (1.7) and 4.6 (1.6), respectively with a $p$-value $<0.001$. The mean maximum pain scores for the 3 stages were 8 (1.9), 7.7 (2) and 6.8 (2.1), respectively with a $p$-value $<0.001$.

In response to the direct question, "Do you think that the political turmoil affected your level of pain?", the majority of the patients (95 patients, 79.2\%) thought that their level of pain was not affected by the political turmoil while $5(4.2 \%)$ and $20(16.7 \%)$ of them thought that their pain levels were decreased and increased due to the political turmoil, respectively (Table 2).

Anxiety slightly increased during the demonstrations but declined after the demonstrations (Figure 2). Similar significant patterns of minimum, average, and maximum anxiety are shown.
Table 2 Effects of political turmoil on the patients' level of pain

\begin{tabular}{ll}
\hline Effects & Number (\%) \\
\hline No effect & $95(79.2)$ \\
Alleviated pain & $5(4.2)$ \\
Aggravated pain & $20(16.7)$ \\
\hline
\end{tabular}

The mean minimum anxiety scores \pm S.D. prior to the demonstrations, during the demonstrations, and under the military junta were 2.2 (2.4), 2.8 (2.4) and 1.3 (1.7), respectively with a $p$-value $<0.001$. The mean average pain scores for the 3 periods were 2.8 (2.7), 3.5 (2.8), and 1.8 (2), respectively with a $p$-value of 0.008 . The mean maximum pain scores for the 3 stages were 3.8 (3.5), 4.8 (3.6), and 2.9 (2.9), respectively with a p-value of 0.03 .

The mean minimum, average, and maximum stress scores of the patients prior to and during the demonstrations, as well as under the military dictatorship are shown in Figure 3.
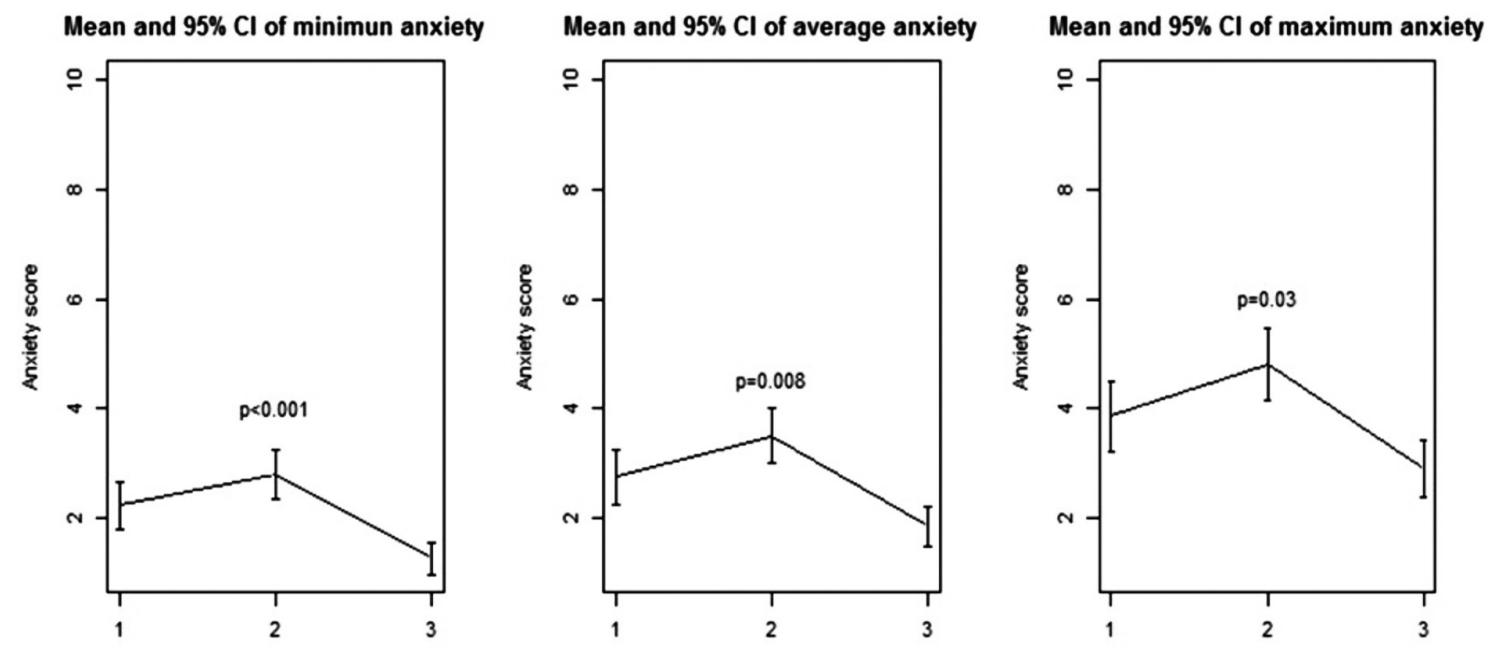

$1=$ prior to the demonstrations, 2=during the demonstrations, 3=under the military junta

$\mathrm{Cl}=$ confidence interval

Figure 2 The mean minimum, average, and maximum anxiety scores of the patients prior to and during the demonstrations, as well as under the military junta 

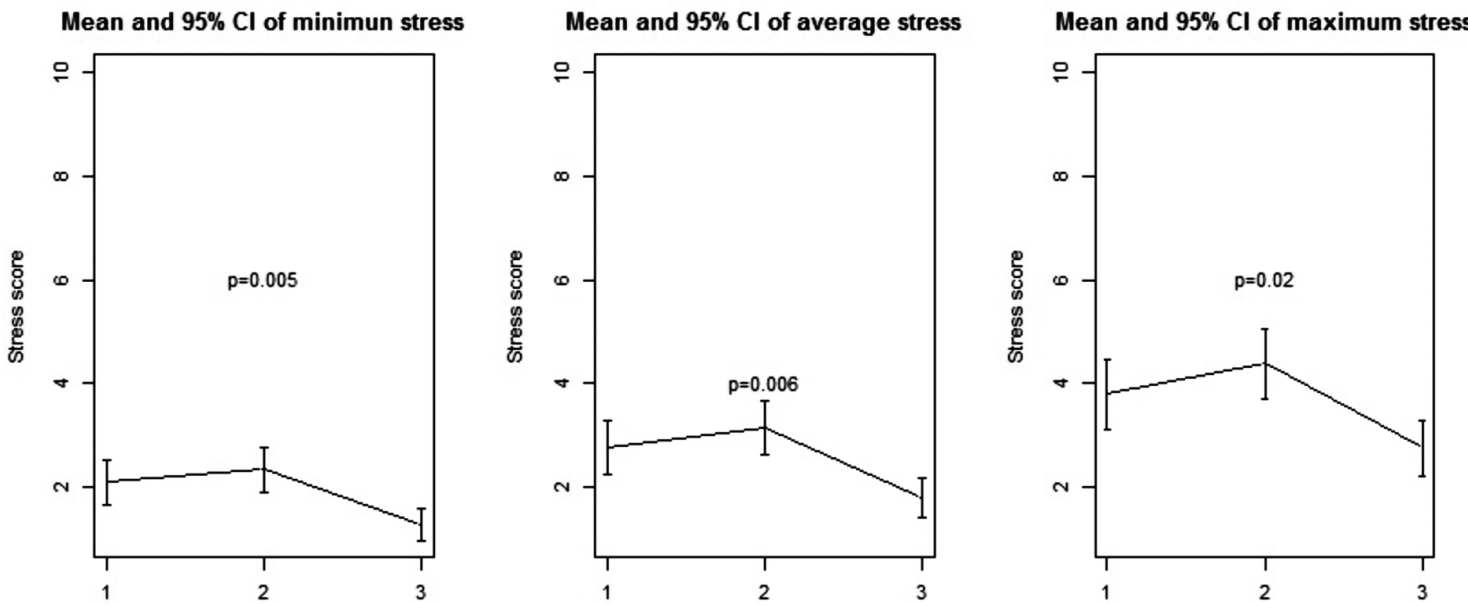

$1=$ prior to the demonstrations, $2=$ during the demonstrations, $3=$ under the military junta $\mathrm{Cl}=$ confidence interval

Figure 3 The mean minimum, average, and maximum stress scores of the patients prior to and during the demonstrations, as well as under the military junta

The mean minimum stress scores \pm S.D. prior to the demonstrations, during the demonstrations and under the military junta were 2.1 (2.4), 2.3 (2.4), and, 1.3 (1.7) respectively with a $p$-value of 0.005 . The mean average pain scores for the 3 periods were 2.8 (2.8), 3.2 (2.9), and 1.8 (2.1), respectively with a $p$-value of 0.006 . The mean maximum pain scores for the 3 stages were 3.8 (3.7), 4.4 (3.7) and 2.8 (3), respectively with a p-value of 0.02 .

The effects of the political turmoil on the patients' daily activities and sleep are shown in Tables 3 and 4, respectively.

The significant changes in pain, anxiety, and stress scores over time by analysis of variance were confirmed by the linear mixed-effects model fit with maximum likelihood. No associations of gender, age, religious, duration of pain, as well as anxiety, nor stress levels and change in pain scores from prior to and after the demonstrations were found.
Table 3 Effects of political turmoil on the patients' daily activities

\begin{tabular}{ll}
\hline Effects & Number (\%) \\
\hline None & $41(34.2)$ \\
Slight & $32(26.7)$ \\
Moderate & $36(30.0)$ \\
Marked & $11(9.2)$ \\
\hline
\end{tabular}

Table 4 Effects of political turmoil on the patients' sleep

\begin{tabular}{ll}
\hline Effects & Number (\%) \\
\hline None & $81(67.5)$ \\
Slight & $21(17.5)$ \\
Moderate & $13(10.8)$ \\
Marked & $5(4.2)$ \\
\hline
\end{tabular}




\section{Discussion}

This study found that the chronic pain patients attending our pain clinic had the highest pain levels for the minimum, average, and maximum scores prior to the demonstrations. Subsequently, their pain levels were lower during the demonstrations and they were at their lowest levels under the military junta. The majority of the patients reported that the political turmoil did not affect their level of pain while a minority thought that the political turmoil either alleviated or aggravated their pain intensity.

Thailand had been in a state of political instability since 2005. The situation did not ease but in fact intensified. The demonstrations took place on 31 October 2013 and lasted for several months until the military completely took control of the situation on 22 May 2014.

Pain is an unpleasant sensory and emotional experience associated with actual or potential tissue damage, or described in terms of such damage. ${ }^{1}$ Pain is considered as chronic when it has persisted for more than 3 months. $^{2}$ There is no one-to-one correlation between the nature or quantity of biological pathology and the level of pain, but instead, the chronic pain experience is multifactorial and formed by biomedical, psychosocial (eg. beliefs, expectations, mood), and behavioral contexts. ${ }^{3}$

Thailand had serious and stressful political turmoil for many years, which the authors supposed would lead to higher pain levels in our chronic pain patients. Surprisingly, the results indicated that the political turmoil did not increase pain intensity. Moreover, the level of pain was found to be lower during the demonstrations when the intensity of the political turmoil reached its peak. We directly asked the patients "Do you think that the political turmoil affected your level of pain?”. Approximately $80.0 \%$ replied that the political turmoil did not have an effect on their pain intensity. This may be one of the reasons why their pain did not increase during the demonstrations. Distractions may also be another reason for having less pain during the demonstrations. Focusing on ideas or actions which distract attention from pain is generally utilized and considered as an effective approach to pain control. ${ }^{4}$ Engaging in political thoughts and activities might have distracted our patients from their pain. Reducing attention to their pain might have led to less pain intensity. Apart from these possible influences contributing to having less pain during the demonstrations, good adherence to a pain regime ${ }^{5}$ may be represented partly as a factor for better pain control during the demonstrations. Even the spontaneous lessening of pain as per the natural course of a disease ${ }^{6}$ may also have been another cause of pain reduction during the demonstrations.

As expected, among the 3 periods of this study, the level of pain was at its lowest under the military junta. Ease of the situation under the guidance of the army, good pain management adherence or the natural reduction of pain may be the reasons for having less pain in this particular period.

Apart from the effects of the political turmoil on the pain intensity of the chronic pain patients attending our pain clinic, we also wanted to know its effects on anxiety and stress levels, as well as during daily activities and sleep.

Anxiety is defined by the American Psychological Association as "An emotion characterized by feelings of tension, worried thoughts and physical changes like increased blood pressure. They may also have physical symptoms such as sweating, trembling, dizziness and a rapid heartbeat". 7 Regarding the effects of the political turmoil on the level of anxiety, we have found that anxiety levels were not high prior to the demonstrations, and reached their highest during the demonstrations. As expected, the level of anxiety significantly dropped under the military junta when people felt more trusting and secure in the safety of the country and additionally had more hope for the future of Thailand. 
The World Health Organization (WHO) assumes that around $1 / 3$ to $1 / 2$ of people who sustain political violence will suffer from some kind of mental distress, including posttraumatic stress disorder (PTSD), depression or anxiety. It was demonstrated that anxiety increased from 26.2 to $47.7 \%$ in adults exposed to political violence during the People's War in Nepal. ${ }^{9}$ In Thailand, even though the political violence was not as severe as in Nepal, as defined by the $\mathrm{WHO}^{10}$, nonetheless, the Thai political turmoil and instability were likely to be the major causes of increased anxiety levels during the demonstrations.

Apart from the levels of pain and anxiety, we have also collected the data of the level of stress caused by the political turmoil. Stress is our brain and body's mode of responding to any type of demand or inappropriate level of pressure. We found that the patients with chronic pain had anxiety before the demonstrations and that the level of anxiety reached its peak during the demonstrations. The anxiety level was at its lowest level when the demonstrations ended and the country came under the military junta. These findings show that the demonstrations led to significantly increased stress levels. Under the military junta, no demonstrations are allowed and the country has been under control with less violence and is thus more peaceful, leading to a significant reduction of stress. We did not collect data on the symptoms of posttraumatic stress disorder; therefore, we cannot compare our findings about the stress levels caused by the political turmoil with the other studies which focused on PTSD, not merely stress.

We asked our chronic pain patients about the effects of the political turmoil on their daily lives and sleep habits. The majority of them reported that the political turmoil affected their daily lives while a minority reported its effect on their sleep habits. There is a possibility that our chronic pain patients paid attention to the political activities during the day, distracting them from doing their jobs or relaxing leisurely. However, our patients did not suffer from sleep disturbances because of the political turmoil, either because they were able to put this issue out of their minds while they rested, or they took pain killers with a sedating effect at night.

Using multiple logistic regression analysis, no factors were found that contributed to the reduction of the level of pain. The factors considered included gender, age, religious, duration of pain, as well as anxiety and stress levels. In patients with plantar heel pain, symptoms of anxiety and stress were found as being independently associated with the pain. ${ }^{11}$

This study has a number of strengths. It is the first study of its kind to evaluate the association between pain intensity in chronic pain patients and political turmoil, not only in Thailand but in the world. Furthermore, it is the first study to assess the correlation of pain intensity at 3 different periods of time: before the demonstrations (political turmoil started far ahead of the demonstrations), during the demonstrations, and under the military junta (after the demonstrations). Apart from the pain intensity, this study is the first to focus on the relationship between the intensity of anxiety and stress in regards to the political turmoil which included the 3 periods of time as described above.

The weakness of this study is its retrospective nature. Recall bias could affect the reliability of the data. Future studies of this issue are recommended.

\section{Conclusion}

In our patients who attended the pain clinic, their pain level did not increase during the demonstrations. On the other hand, the levels of anxiety and stress significantly reached their peaks during the demonstrations. Under the military junta (which ended the demonstrations), the levels of pain, anxiety and stress decreased significantly. 


\section{References}

1. Merskey $H$, Bogduk N. Part III: pain terms, a current list with definitions and notes on usage. In: Merskey $\mathrm{H}$, Bogduk $\mathrm{N}$, editors. Classification of chronic pain. $2^{\text {nd }}$ ed. Seattle: IASP Press; 1994;p.209-14.

2. Treede RD, Rief W, Barke A, Aziz Q, Bennett MI, Benoliel R, et al. A classification of chronic pain for ICD-11. Pain 2015;156: 1003-7.

3. Dansie EJ, Turk DC. Assessment of patients with chronic pain. $\mathrm{Br} J$ Anaesth 2013;111:19-25.

4. Johnson $\mathrm{MH}$. How does distraction work in the management of pain? Curr Pain Headache Rep 2005;9:90-5.

5. DiMatteo MR, Giordani PJ, Lepper HS, Croghan TW. Patient adherence and medical treatment outcomes; a meta-analysis. Med Care 2002;40:794-811.

6. Garaffa G, Trost LW, Serefoglu EC, Ralph D, Hellstrom WJ.
Understanding the course of Peyronie's disease. Int $\mathrm{J}$ Clin Pract 2013;67:781-8.

7. American Psychological Association. Anxiety [homepage on the Internet]. Washington: APA; 2016 [cited 2016 Jul 17]. Available from: http://www.apa.org>topics>anxiety

8. World Health Organization. The world health report 2001 - Mental health: new understanding, new hope. Geneva: W. Press; 2001.

9. Kohrt BA, Hruschka DJ, Worthman CM, Kunz RD, Baldwin $\mathrm{JL}$, Upadhaya $\mathrm{N}$, et al. Political violence and mental health in Nepal: prospective study. Br J Psychiatry 2012;201:268-75.

10. World Health Organization. World report on violence and health. Geneva: WHO; 2002.

11. Cotchett M, Munteanu SE, Landorf KB. Depression, anxiety, and stress in people with and without plantar heel pain. Foot Ankle Int 2016;37:816-21. 